(RESEARCH ARTICLE)

\title{
Extraction of tannins from Punica granatum peel for pharmacological activities
}

\author{
Sayed Muhammad Amin Sadat * and Anisa Omari \\ Lecturer in Synthesis of Organic Material Department, Chemical Engineering Faculty, Jawzan University, Afghanistan.
}

Publication history: Received on 13 October 2020; revised on 22 October 2020; accepted on 24 October 2020

Article DOI: https://doi.org/10.30574/wjarr.2020.8.1.0376

\begin{abstract}
Punica granatum L. (Pomegranate) is utilized in the treatment of parasitic contamination, loose bowels and ulcers. Extracts of the various parts of P. granum is reported to have anti-inflammatory, antioxidant and anticarcinogenic activities. Tannins are a group of polyphenolic compounds that are widely present in plant regions and possess various biological activities including antimicrobial, anti-parasitic, anti-viral, antioxidant, anti-inflammatory, immunomodulatory activities. This study focused on extraction of tannins from Punica granatum peel which can be further analyzed for its pharmacological activities. The results of this study revealed the abundance of tannins in the pomegranate peel extract. Tannins from pomegranate peel might contribute to the high antioxidant activity of this fruit peel and it is a valuable natural antioxidant source applicable in the health food industry.
\end{abstract}

Keywords: Tannins; Pharmacology; Punica granatum; Thin layer chromatography

\section{Introduction}

Punica granatum L. belongs to the family Lythraceae (previously Punicaceae) and is known to be a nutritious fruit containing phytochemical compounds [1]. There are numerous chronicled references in history for utilization of pomegranate as food and medication [2]. Pomegranate has been recorded in old occasions in the Old Bible, the Jewish Torah, and referenced a few times in the heavenly Quran where it was recorded as one of the heavenly organic products. Pomegranate, in ayurvedic medication, is utilized in the treatment of parasitic contamination, loose bowels, and ulcers. As of late, pomegranate has been concentrated in a few medications for its pharmacological activities: antiinflammatory, antioxidant, and anticarcinogenic. Pomegranate wastes are delivered in all the periods of the natural product life cycle that is during farming production, processing and handling. It is conceivable to exploit pomegranate wastes like its peel as they are rich in bio dynamic compounds, for example, flavonoid, and phenolic acids.

Phenolic compounds are pervasive in most medicinal plants and comprise a basic part in the eating routine of humans because of their cancer prevention agent and numerous other healthcare properties [3]. Polyphenols are secondary metabolites with in excess of 8000 phenolic compounds. Polyphenols are known for their pharmacological properties, for instance as anti-inflammatory, antioxidants, anti-mutagenic, anti-carcinogenic, and antimicrobial. Pomegranate is known to contain significant measure of phenolic compounds, including anthocyanins, tannins, ellagic corrosive, punicalin, punicalagin, pedunculagin and different flavanols are the fundamental gathering of cancer prevention agent phytochemicals that are significant because of their organic and free radical scavenging properties [4]. In a similar examination, anthocyanins from pomegranate organic products were found to have higher antioxidant property than nutrient $\mathrm{E}(\alpha$ - tocopherol), $\beta$ - carotene, and ascorbic acid.

Extracts of all parts of the pomegranate fruit exhibit therapeutic properties and target a range of diseases including cancer, cardiovascular disorders, diabetes, male infertility, Alzheimer's disease, aging, and AIDS. Pomegranate peels are considered a waste product generally used as animals feed without any added value despite the high content of

\footnotetext{
* Corresponding author: Sayed Muhammad Amin Sadat

Lecturer in Synthesis of Organic Material Department, Chemical Engineering Faculty, Jawzan University, Afghanistan.
} 
polyphenolic compounds that are more important than that contained in the edible part of the fruit. The polyphenolic compounds of the Pomegranate peels have important health properties because of their antioxidant, anti-inflammatory and antimicrobial properties [5]. These properties provide the Pomegranate peels with a great potential to be used as an attractive ingredient and natural additive for food enrichment. Otherwise, different applications are associated with the presence of hydrolysable tannins (ellagitannins), flavonoids (anthocyanins) and condensed tannins (proanthocyanidins) such as dye and ecological adhesive applications [6] [7]. In this context, the present study optimized tannins extraction conditions, characterized the resulting extract and compared yield extraction from fresh and dried Pomegranate peels. It appears that fresh form of this agro-industrial waste has higher polyphenolic content than its dried form, whereas, generally, Pomegranate peels is valorized in the form of dry agriculture waste.

Tannins are a group of polyphenolic compounds that are widely present in plant regions and possess various biological activities including antimicrobial, anti-parasitic, anti-viral, antioxidant, anti-inflammatory, immunomodulation. Considering the earlier studies, data strongly endorse that tannins will be an effective approach for inhibiting inflammatory activity [8]. The main phenolic acids identified and quantified were ellagic acid, gallic acid, cinnamic acid, chlorogenic acid and coumaric acid [9]. This study focused on extraction of tannins from Punica granatum peel which can be further analyzed for its pharmacological activities.

\section{Methodology}

\subsection{Preparation of Methanolic extract}

Punica granatum (Pomegranate) peel was naturally dried on trays away from sunlight at room temperature. The dry weight of the peel was measured and powdered to obtain particles using an 80-mesh size. Ten grams of pomegranate peel was added to $200 \mathrm{~mL}$ of $80 \%$ methanol in a $250 \mathrm{~mL}$ conical flask and was extracted in a Soxhlet apparatus. The final extract was dried and stored at $4{ }^{\circ} \mathrm{C}$ until used for follow-up studies.

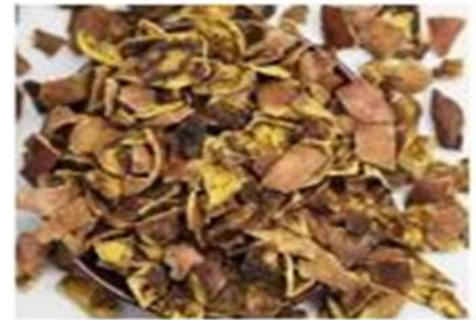

Dried Pomegrante peel

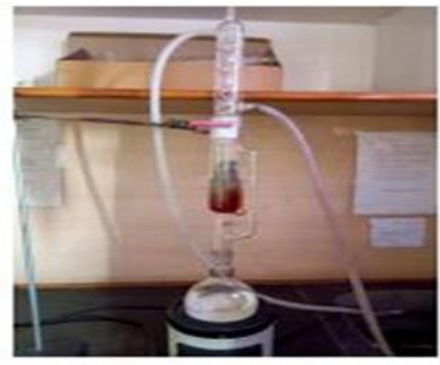

Soxhlet extraction of tannins

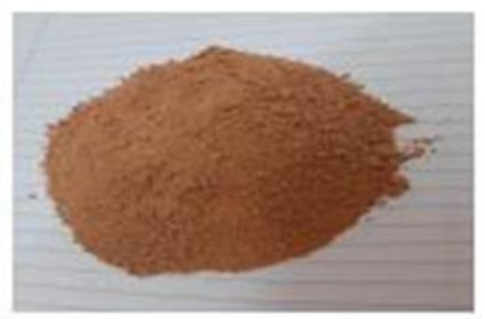

Pulverized Pomegrante peel

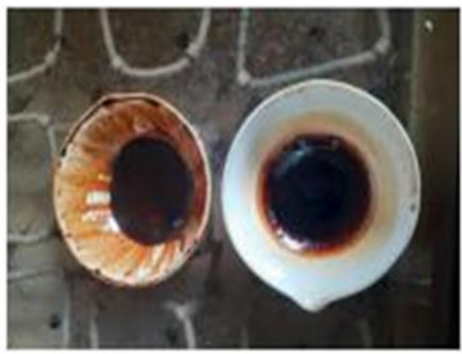

Tannin extract from Pomegrante peel

\subsection{Test for tannins}

Tannin from the pomegranate peel extract was determined by mixing $5 \mathrm{ml}$ of extract, $5 \mathrm{ml}$ of distilled water in a test tube along with $3-4$ drops of $0.1 \%$ of ferric chloride. The change of reaction mixture colour to blue color indicates the presence of tannins [10].

\subsection{Thin layer chromatography}

The sample and standards were separately spotted as bands on pre coated silica gel aluminum plate. The mobile phase consisted of chloroform: methanol: formic acid (85: 10: $5 \mathrm{v} / \mathrm{v}$ ). The total TLC plate height in a horizontal tough glass chamber, which was saturated with mobile for 30 minutes at room temperature. The plate was dried in current air or with an air drier [11]. 


\section{Results and discussion}

In the present study, extraction of P. granatum peels with $80 \%$ methanol gave a deep brown color extract with percent yield of dried weight of sample 29.1\%. Medicinal plants possess a wide range of bioactive compounds, tannins are the widest occurring one and have been touted as accounting for most of the antioxidant activity of plants or plant products.

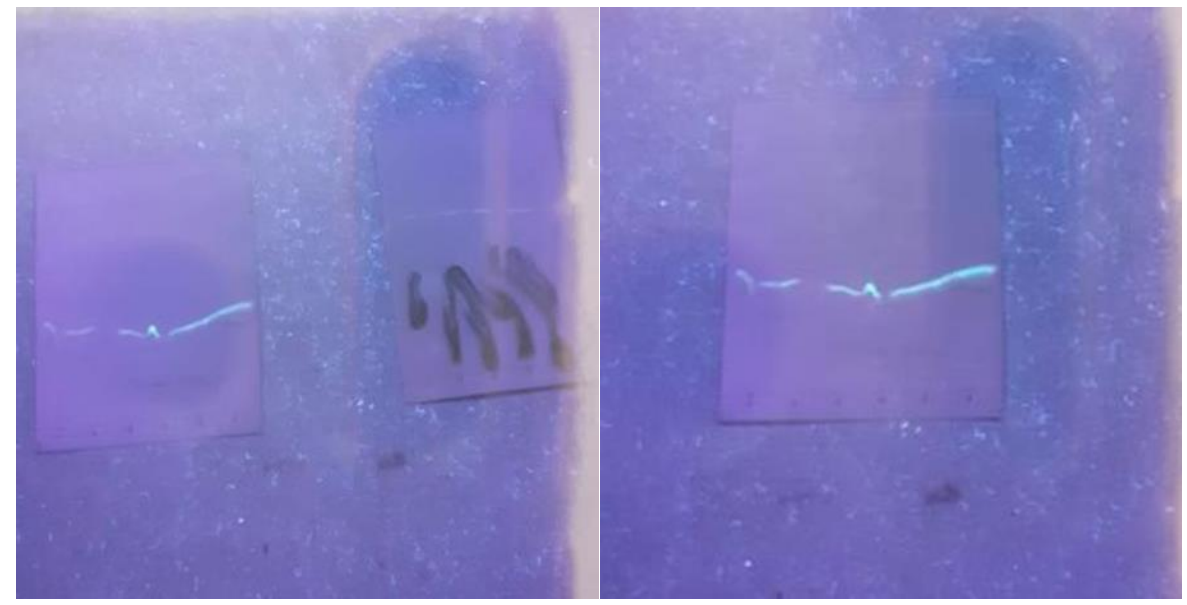

Figure 1 Thin Layer Chromatography of Pomegranate peel extract

Tannins are water soluble polyphenols that present in many different parts of plants [12]. Tannins also play an important role in acceptability of food products and their chemical structures are different, though they have a distinguishing astringent taste [13]. Tannin compounds classified into two groups: hydrolyzable tannins, and; non hydrolyzable tannins. The first one is ester of phenolic acids with sugars [14]. Tannins compounds were used in many industrial applications, such as juices clarification and antioxidant material when added to many food products and beverages [15], also in oil refining and in preservation of marine meat fish and in manufacture of blue ink [16] and a component of cosmetic products and pharmacological drugs due to their activity against chronic dysentery, stimulating healing and treatment cholera and its best antidote against poisonous mushrooms [17]. The literature reported that tannin occupied $25-30 \%$ of the dry pomegranate peel [18].

When a new drug to be discovered, qualitative phytochemical analysis is a very important step as it gives information about the presence of any particular primary or secondary metabolite in the extracts of the plant which is having a clinical significance. This study proved the abundance of tannins in the Pomegranate peel extract. We are expecting these tannins might have a role in different diseases.

\section{Conclusion}

This study suggests the isolated tannins might contribute to the high antioxidant activity of this fruit peel and it is a valuable natural antioxidant source applicable in the health food industry.

\section{Compliance with ethical standards}

\section{Acknowledgments}

The authors are grateful to Jawzan University, Afghanistan for the support.

\section{Disclosure of conflict of interest}

The authors declare that there is no conflict of interest.

\section{References}

[1] Usha T, Middha SK, Bhattacharya M, Lokesh P, Goyal AK. Rosmarinic Acid, a New Polyphenol from Baccaurea ramiflora Lour. Leaf: A Probable Compound for Its Anti-Inflammatory Activity. Antioxidants (Basel). 2014; 3(4): 830-842. 
[2] Holland D, Hatib K, and Bar-Yaakov I. Pomegranate: Botany, Horticulture, Breeding. 2009. Horticultural Reviews, Volume 35 Edited by Jules Janick Copyright. John Wiley \& Sons, Inc.

[3] Balasundaram N, Sundram K, Samman S. Phenolic compounds in plants and agri-industrial by-products: Antioxidant activity, occurrence, and potential uses. Food Chemistry. 2006; 99: 191-203.

[4] Khan N, Ahmed A, Hadi S. Antioxidant, Prooxidant properties of tannic acid and it's binding to DNA, Chem. Biol. Interact. 2000; 125.

[5] Xi J, He L, Yan L-G. Continuous extraction of phenolic com- pounds from pomegranate peel using high voltage electrical discharge. Food Chem. 2017; 230: 354-361.

[6] Ajmal M, Adeel S, Azeem M, Zuber M, Akhtar N, Iqbal N. Modulation of pomegranate peel colourant characteristics for textile dyeing using high energy radiations. Ind Crops Prod. 2014; 58: 188-193.

[7] Saad H, Bouhtoury FC-E, Pizzi A, Rode K, Charrier B, Ayed N. Characterization of pomegranate peels tannin extractives. Ind Crop Prod. 2012; 40: 239-246.

[8] Huang Q, Liu X, Zhao G, Hu T, Wang Y. Potential and challenges of tannins as an alternative to in-feed antibiotics for farm animal production. Anim. Nutr. 2018; 4(2): 137-150.

[9] Farag RS, Abdel-Latif MS, Abd El Baky HH, Tawfeek LS. Phytochemical screening and antioxidant activity of some medicinal plants' crude juices. Biotechnology Reports. 2020. 28: e00536.

[10] Goyal BR, Agrawal BB, Goyal RK, Mehta AA. Phyto-pharmacology of Moringa oleifera Lam. - An overview. Natural Product Radiance. 2007; 6: 347-353.

[11] Jayachandran Nair C V, Ahamad S, Khan W, Anjum V, Mathur R. Development and validation of high-performance thin-layer chromatography method for simultaneous determination of polyphenolic compounds in medicinal plants. Phcog Res 2017;9, Suppl S1:67-73

[12] Akiyama H, Fujii K, Yamascki O, Oono T, Iwatsuki T. Antibacterial action of several tannins against Staph. aureus. J. of Antimicrobial Chemotherapy. 2001; 48: 487-491.

[13] Chung K, Wong T, Wei T, Huang Y. Tannins and human health. Critical Reviews in Food Science and Nutrition. 1998; 38: 421- 464.

[14] Scalbert A. Antimicrobial properties of tannins. Phytochemistry. 1991; 30: 3875-3883.

[15] Khan N, Ahmed A, Hadi S. Antioxidant, Prooxidant properties of tannic acid and it's binding to DNA, Chem. Biol. Interact, 2000; 125: 177-189.

[16] Huang Y, Low L, Chung K, Huang C. Effect of tannic acid, gallic acid and propyl gallate on storage life of cat fish, Proceeding: Tropical and Subtropical Fishers Technological Conference of the Americans. University of Florida. 1993; 324-239.

[17] Chung K, Stevens S, Lin W, Wei C. Growth inhibition of selected food born bacteria by tannic acid, propylgallate and related compounds. Letters in Applied Microbiology. 1993; 17: 29-32.

[18] $\mathrm{Hu}$ HL, Ning HL. The tannin of distill in Kashgar pomegranate peel and seeds. J Xinjiang Univ Nat Sci Ed. 2007; 24(1): 73-76. 